Fecha de recepción: mayo 2021 Fecha de aceptación: junio 2021 Versión final: julio 2021

\section{La Shoá: Memoria, identidad y trauma en el cine alemán de nuestros días. Ave Fénix (Petzold, 2015)}

María Elena Stella ${ }^{(1)}$

Resumen: La memoria de la Shoá ha seguido una evolución diacrónica de enorme envergadura. En efecto, desde la incomprensión y ocultamiento del suceso, en la inmediata posguerra, pasó a convertirse, en nuestros días, en la "religión civil de Occidente", según Enzo Traverso (2011). Este devenir no está desconectado del nuevo régimen de historicidad - el modo con que una sociedad se relaciona con la tríada temporal pasado, presente y futuro- que afecta a la política y la cultura en la época de la globalización.

Desde hace cuatro décadas, con el colapso de la idea de progreso que sostenía la Modernidad, el futuro perdió su carácter prioritario y orientador y su lugar pasó a ser ocupado por el pasado, pero no por un pasado del cual es posible extraer lecciones útiles, sino una historia poblada de genocidios, guerras, violaciones de los derechos humanos, es decir, un pasado que debía ser, permanentemente, recordado para que no vuelva a repetirse.

La centralidad del pasado violento favoreció la incorporación de la categoría de trauma, que, importada del campo del psicoanálisis y de los fenómenos que influyen en la psique individual, sirvió para explicar los hechos de violencia que afectaron a grandes grupos humanos. De este modo, el hecho traumático, la negación, la amnesia, la anamnesis y el retorno de lo reprimido fueron incorporados al campo semántico de las masacres masivas de los siglos XX y XXI, legando dicho potencial explicativo a la Historia y a la memoria social.

El suceso traumático -individual o colectivo- afecta a la construcción de la identidad, excede los marcos de referencia conocidos, necesarios para la narración, rompe las cadenas causales con las que las personas o grupos elaboran el trauma.

La caída del Muro de Berlín, la siguiente reunificación alemana propiciaron el proceso de elaboración del pasado violento y la construcción de una nueva identidad alemana pluralista, democrática, que se hace cargo, juzga y condena el pasado nacional socialista. Los procesos convergentes, antes descriptos, las distintas etapas de la memoria de la Shoá, de la elaboración del trauma y de la construcción de nuevas identidades grupales e individuales están representados, entre otras producciones audiovisuales, pero en forma paradigmática, en la película Ave Fénix, dirigida por Christian Petzold, (2015), de cuyo análisis fílmico, imágenes, discursos, de su contexto histórico social y cinematográfico se ocupará el presente artículo.

Basada en la novela del escritor francés Hubert Monteilhet, Le retour des cendres, publicada a comienzos de la década del sesenta, Ave Fénix, se ubica en la Alemania de 1945 y narra el regreso de una sobreviviente de los campos de concentración nazi, tema que, 
según el director, había sido eludido por el cine alemán y cuya memoria juzgaba necesario restituir. La exprisionera retorna del horror, no soló con el trauma de la experiencia límite vivida, sino con su cara desfigurada por un disparo de ametralladora. La búsqueda de una explicación que resulta esquiva, la dificultad de narrar lo sucedido, la reconstrucción de su identidad y de su rostro constituyen la metáfora del trauma colectivo, el intento de comprensión y de elaboración del Holocausto.

Palabras clave: Holocausto - Sobrevivientes - Identidad - Memoria - Cine.

[Resúmenes en inglés y portugués en la página 279]

${ }^{(1)}$ Historiadora (Facultad de Filosofía y Letras - UBA). Docente e investigadora de la Universidad de Buenos Aires. Profesora de Historia Económica y Social Argentina en la Facultad de Ciencias Económicas y de Introducción al Conocimiento de la Sociedad y el Estado en el Ciclo Básico Común. es, también, Profesora del Instituto de Enseñanza Superior del Profesorado $\mathrm{N}^{\circ} 1$ Dra. Alicia Moreau de Justo. Se ha dedicado a la investigación de la relación entre cine e historia, particularmente, de cine y genocidio.

\section{Introducción}

La segunda década del presente siglo encuentra a Alemania ya avanzada en la tarea de construir una identidad nacional democrática e inclusiva, que había comenzado hacía tiempo y en sucesivas etapas, la última de ellas fuertemente impulsada por la caída del Muro de Berlín y la necesidad de crear una memoria a contrario de la fenecida Alemania Oriental, cuya imagen quedó integrada al autoritarismo estalinista (Fulbrook, 1995, p. 285-351)

Luego de cuarenta y cinco años de división impuesta por las potencias vencedoras de la Segunda Guerra Mundial, institucionalizada, poco después, en el contexto de la Guerra Fría, Alemania reunificada se presenta ante el mundo diferenciándose al mismo tiempo de las dos experiencias totalitarias que oscurecieron su pasado reciente.

El período nacionalsocialista y la Shoá cobraron una dimensión fundamental en la creación de la nueva identidad democrática, pluralista, con memoria de ese pasado que era menester recordar, permanentemente, como guardián del presente y del futuro. Asimismo, las etapas caracterizadas por el olvido de tales eventos, los silencios y el intento cerrar el pasado nazi fueron cuestionadas y asociadas al ocultamiento de la verdad, la impunidad de los perpetradores y la revictimización de los que padecieron la violencia. En la llamada 'era Adenauer's se materializa esta actitud de elisión de la responsabilidad alemana y retroceso de la justicia penal. (Romeyke, 2016, p. 8-44) 
No obstante, a finales de la década del cincuenta, tuvo lugar un proceso de anamnesis o revisión del pasado, cuya figura más representativa fue la del fiscal Fritz Bauer, quien puso en marcha los Procesos de Auschwitz en Frankfurt sustanciados entre 1963-65 y uno de los artífices de las investigaciones que dieron con el paradero de Adolf Eichmann y su posterior juzgamiento. ${ }^{2}$

Contra aquellos que sostenían que avanzar en la justicia penal significaba un peligro para la democracia naciente, el Fiscal de Hesse, aprovechaba todas las tribunas, incluidos los programas de televisión, para remarcar que democracia y justicia son inseparables, siendo esta última el basamento más firme para consolidar un sistema auténticamente democrático. A partir de la década del noventa del siglo pasado, Fritz Bauer, pasará a ser una de la figuras más valorizadas, ubicada en un lugar central de la nueva memoria e identidad alemana.(Stella, 2019, p. 150-152)

En sintonía con esta precepción que se ha instalado en el espacio público y reforzándola, surgió una amplia filmografía alrededor de su figura (Stella, 2018) y (Stella, 2019), entre ellas, los filmes de Ilona Ziok, Fritz Bauer, muerte a plazo (Death By Instalments) de 2010; Giulio Ricciarelli, Laberinto de mentiras (2014); Lars Kraume, Agenda Secreta (2015) y de Stephan Wagner, El expediente general (2016).

Surgida en ese contexto histórico, cultural y cinematográfico, Ave Fénix participa del juego de espejos e identificaciones, hasta tal punto que la misma está dedicada al Fiscal Fritz Bauer, homenaje que queda expresado ni bien finaliza la historia y se oscurece la pantalla.

\section{Ave Fénix, Petzold, Alemania, 2015}

Christian Petzold es un director germano nacido en 1960, quizás el mejor representante de la denominada Escuela de Berlín, considerada como una cantera del nuevo cine alemán del siglo XXI. ${ }^{3}$ Dicha escuela se integra de un grupo de cineastas de producción heterogénea pero con algunos puntos en común como son el compromiso con la realidad presente y pasada, la renuncia a los grandes relatos y su preferencia por la narración de pequeñas historias, protagonizadas por personajes sin ideas preconcebidas, ni fuertes certezas .

Petzold organiza su filmografía en base a trilogías. Bárbara (2012), Ave Fénix (2015) y Transit (2018) conforman una de ellas. Las tres son relatos de amor entre personajes en situación de tránsito, que huyen de las violencias de estado, de contextos opresivos. Bárbara está ambientada en Alemania Oriental, bajo la dictadura comunista, mientras que Transit es una distopía de Europa, en un futuro muy cercano, dominada por regímenes autoritarios y racistas que reprimen y deportan a los inmigrantes africanos, árabes y latinoamericanos.

El tema que aborda Ave Fénix es el regreso de los deportados de los campos de concentración nazis, al final de la Segunda Guerra Mundial, cuestión que para el director había sido eludida por el cine alemán durante décadas a diferencia de otros países cuya cinematografía registró ese momento dramático: cuando cesa el fuego, finaliza la guerra pero no hay paz, perdura el dolor, la indiferencia y los odios. ${ }^{4}$ Restituir esta cuestión a la memoria con una ficción cinematográfica significaba para Petzold una especie de redención para con las víctimas del Holocausto. 
La idea había surgido a principios de la década del ochenta, cuando su maestro, mentor y coguionista, Harun Farocki, le presentó la novela poco conocida a la sazón del escritor francés Hubert Monteilhet, Le retour des cendres, -traducido literalmente, El retorno de las cenizas ${ }^{-}$. El recurso a la metáfora del ave mitológica como regeneración luego del haber vivido el horror de los campos estaba ya presente en la historia original, pero mientras ésta transcurre en Francia, Petzold la traslada a Berlín en 1945.

Ave Fénix es un melodrama, de estética noir y una música sentimental evocadora, indispensable en la historia de una cantante judía, Nelly Lenz, que ha sobrevivido a Auschwitz y regresa a una Berlín destruida, hecha escombros y cenizas. Este último es un componente omnipresente y polisémico que atraviesa todo el filme. Es fácil advertir la impronta de su admirado, Rainer Werner Fassbinder, uno de los directores más destacados del Nuevo Cine Alemán.

El personaje no sólo carga con el trauma de la experiencia del lager, sino que tiene el rostro desfigurado por un disparo de ametralladora, impacto de tal magnitud que había hecho pensar a todos que estaba muerta. Pero no fue así, sobrevivió y retornaba con la voluntad de reconstruirse física y mentalmente. Para reparar el estrago de su cara, recurre a un cirujano, quien le señala la ventaja de "recrear el rostro" sin conservar los rasgos anteriores, coherente con la actitud de borrar el pasado. Postura compartida por Lene, su amiga, también víctima del nazismo, que le propone abandonar Alemania y emigrar a Haifa o a Tel Aviv para construir una nueva vida y empezar de cero. Sin embargo, Nelly insiste en recuperar su mundo familiar y social previo a la catástrofe. La diferencia es no es para nada sutil: olvidar o elaborar el trauma.

De su pasado, Nelly ha rescatado una foto donde está ella con su antiguo núcleo de amigos, sobre cada uno de ellos hay una marcación: algunos rostros tienen un círculo que significa que adhirieron al régimen nazi y los otros que presentan una cruz, son las víctimas del nacionalsocialismo.

Nelly Lenz está empecinada en reencontrarse con su marido, Jony, sobre el que pesa una fuerte sospecha, más tarde comprobada: fue su denunciante y entregador. Aunque Lene le había advertido sobre la traición, ella se niega a creer, quiere confiar en su esposo. Su imagen fantasmagórica, iluminada en medio de las penumbras, deambula por la ciudad oscura y amenazante hasta que, finalmente da con él, está vivo y trabaja en un cabaret que, significantemente, tiene el nombre de Fénix. Dado que su aspecto ha sido transformado por la cirugía y otros rasgos físicos, como el caminar lento y titubeante, secuela de los sufrimientos padecidos, el ex marido no la reconoce aunque sí encuentra en esa mujer que dice llamarse, Esther, algo que le recuerda a su esposa.

El mecanismo de la negación para preservarse es común a todos los personajes, cada uno por distintas razones o sentimientos: Nelly no quiere aceptar que su esposo la haya delatado a las autoridades nazis, Jony se niega, subconscientemente, a reconocerla porque no quiere enfrentarse a su propia culpa. La gente que la rodea no quiere escuchar nada del pasado reciente, porque hay algo en él que la incrimina.

El parecido de esta 'desconocida' con su ex mujer le hace pergeñar un plan para poder cobrar la herencia de Nelly, a quien considera muerta al igual que toda su familia. El ardid 
consistía en escenificar el retorno de Nelly, a cambio del acting, 'Esther' , recibiría una buena suma de dinero. La ex deportada acepta la propuesta del pianista porque lo ama y alberga la esperanza de reconstruir su relación, aunque, la sombra de la duda se va agigantando a cada paso.

El centro del argumento del filme es un contrasentido: se trata de alguien que tiene que imitarse a sí misma. Nelly debe fingir que es ella misma y representar su propio regreso. Esta paradoja es una de las tantas dimensiones que asume la cuestión de la identidad en la película.

La estrategia incluía una carta que, supuestamente, escribe Nelly donde anuncia que está viva y va a retornar en forma inminente a Berlín. Para ello, usando como modelo antiguos escritos suyos, ensaya su propia letra y firma, que, por supuesto, resulta idéntica a la original. Jony había planificado, además, la escena del reencuentro con él y sus antiguos amigos en la estación del tren. La pareja había acordado las palabras y maneras más adecuadas para hacer verosímil el encuentro, incluyendo su aspecto, los zapatos y el vestido rojo, que habían pertenecido a la cantante. En ese juego de representaciones Esther - Nelly, se permite señalar que no es creíble que una recién llegada del campo de concentración tenga esa apariencia. Sin embargo, no se trata de un error o una estrategia equivocada, sino algo reflexionado que se adecuaba a la realidad ya que la gente, según el pianista, no quería ver deportados andrajosos y sufrientes sino verlos regresar tal como eran antes, como sin nada o muy poco hubiera ocurrido.

No están dispuestos a escuchar. No quieren saber. Su presencia, sus relatos les traían un pasado que había que olvidar, que los ponía frente a frente con sus responsabilidades sobre la tragedia que acabada de ocurrir. En efecto, a su regreso Nelly encuentra un universo de ocultamiento, silencio y complicidades. Para algunos de sus allegados su presencia resulta inquietante y, aunque sin proponérselo, los culpabiliza. Visita su antigua casa, pregunta a sus vecinos y empleados, quienes, lejos de alegrarse de verla viva, se sienten interpelados. Los caseros han aprovechado su desgracia para apropiarse de su casa y por otra parte, más angustiante aún, le confirman que fue su esposo quien la denunció.

Aunque en cada escena parece inminente la llegada del desenlace, es decir, el descubrimiento - o más bien, la aceptación- de que esa persona que finge ser Nelly es, efectivamente, Nelly, el suspenso se mantiene y la verdad no llega sino al final de la película. El reconocimiento se da, no a partir de la confesión, sino por la voz, inconfundible rasgo de una persona y, particularmente, de una cantante. El otro elemento de identificación y reconocimiento es el número tatuado en brazo que asoma por debajo de la manga: la marca indeleble de Auschwitz.

A diferencia de su amiga, Lene, cuyo final es dramático ya que no pudo soportar la situación postraumática y se suicida, el personaje principal logra una salida. Al entonar en inglés la canción "Háblame suavemente", íntimamente asociada a su pasado, Nelly logra, en un solo acto recuperar la dignidad e la identidad que le había sido arrebatada. No renacerá el amor que antes unía a la pareja y que ahora se encuentra, irremediablemente, dañado, pero sí tiene lugar la resurrección de la mujer, como el Ave Fénix. 


\section{Algunas reflexiones a propósito de la película}

\section{Los cuerpos de la guerra}

La cirugía estética fue un tópico recurrente en la sociedad, la ciencia y el arte desde la Primera Guerra Mundial a raíz de su secuela de cuerpos mutilados y rostros desfigurados. ${ }^{6}$ Finalizada la contienda, las huellas físicas perpetuaban el horror en un recuerdo mortificante, una presentificación perpetua del pasado trágico.

En el campo de la literatura y del arte, el impacto de la violencia en los cuerpos dieron lugar a la proliferación de libros, foto libros, pinturas y esculturas que representaron los estragos causados por las bombas, minas, granadas y balas en la figura humana. Imágenes que apuntaban por elevación a la civilización moderna in toto. El relato del progreso indefinido quedaba desmentido ante un mundo que exhibía, con palmaria elocuencia, las capacidades deletéreas de la tecnología y la ciencia modernas.

Volver a la vida civil, finalizada la guerra, no implicaba un alivio a la dramática situación de los soldados mutilados ya que debían enfrentar el rechazo social y la vergüenza de ser mirados como monstruos, situación angustiante que se agravaba aún más por la dificultad de conseguir trabajo. En todos los ámbitos sociales, resultaban una presencia incómoda. El fenómeno de las gueules cassées - literalmente, bocas rotas- o caras quebradas, fue encarado, al principio, por instituciones integradas por escultores, que hacían máscaras para ocultar las deformidades y restituir dignidad a los rostros. Más importante y duradero fue el impulso que experimentó la medicina en materia de cirugías estéticas y creación de prótesis. Ambas ramas avanzaron a pasos agigantados en el periodo de entreguerras. El cine recogió la temática, particularmente, el género policial, de terror o de suspenso ya que las máscaras y cirugías se prestaban muy bien a las historias de intrigas, sustitución de personas e identidades ocultas ${ }^{28}$. Hubo también varias películas de ficción sobre criminales nazis que recurrían a cirugías estéticas en instituciones clandestinas para cambiar sus fisonomías y así, evitar ser llevados ante los tribunales. ${ }^{7}$ Algunos de estos filmes aparecen como intertextos en los que se inspira y con los que dialoga la película Ave Fénix.

\section{Situación límite y trauma}

Bruno Bettelheim, psicoanalista austríaco, que sufrió en carne propia la experiencia traumática como prisionero en Dachau y Buchenwald, acuñó el concepto de 'experiencia extrema' para referirse a la desintegración de la personalidad que sufren los internados en el lager. Se trata de una situación límite para la cual no hemos sido preparados, cuando se quiebra un orden naturalizado del mundo y los individuos deben adaptarse a un contexto extraño redefiniendo sus identidades y sus relaciones con otros individuos y grupos. En la experiencia extrema los antiguos valores y mecanismos de adaptación ya no funcionan e, incluso, algunos de ellos pueden poner en riesgo la vida que se supone debían proteger. (Loriga, 2018, p. 94-97) 
Para Bettelheim, la experiencia del sobreviviente está enmarcada por una doble temporalidad. En primer lugar, el trauma originario, el momento de la detención y el internamiento, cuando se destruye, totalmente, la vida social del individuo, privándolo de sus apoyos, la familia, los amigos, el núcleo social, al tiempo que lo coloca en un régimen de terror y degradación extremo que incluye la constante amenaza de muerte. Consideremos, además, que el deportado es arrojado a un universo carcelario poblado de una multitud heterogénea de grupos lingüísticos, nacionales, religiosos, una verdadera Babel moderna y terrorífica. (Rees,2005 p. 410-411). En segundo lugar, los efectos de ese trauma perduran, no terminan al ser liberados del campo. A su regreso, el deportado, encuentra enormes dificultades para narrar su experiencia y ponerla en el pasado, imposibilidades que persisten de por vida. Pero, además, se siente culpable por haberse salvado, por regresar del horror mientras que la mayoría no pudo. De alguna manera percibe que la razón por la que ha sobrevivido tiene que ver con alguna traición cometida o por haber claudicado moralmente. Primo Levi, quien, sin duda, ha explorado profundamente las raíces de la culpa, afirma que el primer contacto con la realidad concentracionaria dinamitó los lazos de comunidad y solidaridad, incluso, en el micro grupo de referencia (Loriga, 2018 p. 105), (Levi, p.94) En condiciones límite, el prisionero además de sufrir el abuso, puede verse en la obligación de participar en la violencia contra otros, es decir, se comporta de una manera que él mismo no podría aprobar en condiciones normales.

\section{El regreso de los deportados. Testimonio e identidad}

Sobre las experiencias de los deportados, su identidad y memoria ha reflexionado el sociólogo austríaco de Michael Pollak (2006), quien focaliza no solo en el periodo de permanencia en el campo sino, fundamentalmente, en la etapa posterior, el retorno luego de la experiencia del horror. Mientras que en el campo debe afrontar la tensión constante entre salvar la integridad física y preservar sus valores morales, ante el omnipresente peligro de perder la vida, al momento de liberarse, los individuos se enfrentan a un mundo diferente del que dejaron. Han perdido sus familias, amigos, hogares y deben adaptarse a la nueva realidad con la mochila de los recuerdos invasores y las visiones constantes del lager.

En su análisis de los testimonios de los sobrevivientes, se detiene en las dificultades de las víctimas de preservar los sentimientos de identidad. Para el autor, testimonio e identidad están firmemente entrelazados ya que el primero no pertenece sólo al orden de lo factual sino que a partir del mismo se construye o reconstruye la identidad del deportado.

Su aporte fundamental, posiblemente, sea su explicación sobre la cuestión del silencio ya que, si bien es fácil entender el silencio de los victimarios o simpatizantes del régimen nazi - ocultar sus actos y evitar la penalización- , mucho más complejo es comprender esta conducta por parte las víctimas. Al respecto sostiene que para poder narrar sus sufrimientos una persona necesita, antes que nada, encontrar una escucha. Es decir, la disposición a testimoniar o guardar silencio del sobreviviente está fuertemente condicionada por el contexto social de recepción. Sólo ante una sociedad receptiva, dispuesta a escuchar, el ex deportado puede hacer pública la experiencia vivida. (Pollak, 2006, p. 21) 
La fuente principal seleccionada por Pollak son las memorias de las mujeres deportadas por causas raciales, franja que según el autor, estaba poco representada en el espacio público, dominado por voces masculinas y, sobre todo, de los deportados por causas políticas. A su retorno, los sobrevivientes encontraron un efímero momento de disposición a ser escuchados, pero duró poco, ya que, rápidamente, la tarea de reconstrucción de posguerra absorbió todas las energías de los alemanes y agotó la voluntad de oír el relato del pasado violento. La necesidades materiales del presente se colocaron en el centro de las preocupaciones de la sociedad y del Estado. Pronto desaparecieron en las conmemoraciones oficiales el desfile de los antiguos deportados en ropa rayada que, además de su aspecto lastimero, despertaban sentimientos de culpa, en distintos grados, pero ampliamente expandidos en la sociedad alemana. Para Pollak, (2002, p. 21-22) 1945 organiza el olvido de la deportación, las víctimas del odio racial llegan cuando las ideologías ya están dispuestas, cuando la batalla por la memoria ya había comenzado y la escena política estaba saturada. Sus recuerdos y testimonios sobre el pasado reciente estaban demás en una memoria que consagraba una jerarquía de víctimas, privilegiando a los perseguidos políticos. (Pollak, 2006, p. 30-31)

En este contexto, el silencio de los sobrevivientes, no es olvido ni voluntad de olvidar sino, más bien, una estrategia que intentaba hacer posible su reinserción, sin culpabilizar a una sociedad que le había dado la espalda y que ahora prefería elidir los relatos del horror.

Las razones del silencio son complejas y múltiples, una de ellas tiene que ver con lo indecible, la vergüenza del sujeto ¿Cómo describir con pudor y dignidad los actos que han degradado y humillado a las personas? Con relación al universo que analiza Pollak - las mujeres deportadas por causas no políticas - el silencio puede provenir del motivo por el cual han sido condenadas, la "vergüenza racial", según las leyes de Nuremberg de 1935. Ante lo inefable, la dificultad de dar un sentido al sufrimiento padecido inhibe la narración y favorece la postura del silencio.

\section{Algunos comentarios finales. Imágenes y conceptos.}

Luego de estas reflexiones de historiadores, sociólogos, psicoanalistas que construyeron categorías para hacer entendible aquello que resiste a la comprensión, volvemos al cine porque como dice Deleuze, "los grandes autores de cine podían ser comparados no sólo con pintores, arquitectos, músicos, sino también como pensadores. Ellos piensan con imágenes- movimiento y con imágenes-tiempo, en lugar de conceptos" (...) y por ello "el cine forma parte de la historia del arte y del pensamiento, bajo las insustituibles formas autónomas que estos autores supieron inventar y, a pesar de todo, hacer visibles." (Deleuze, 2007, p.11)

El realizador de Ave Fénix, Christian Petzold, es consciente de las dificultades que conlleva la representación del Holocausto y, es por eso que, partiendo de la conocida frase de Theodor Adorno: "No hay poesía después de Auschwitz", considera que Auschwitz no es filmable pero lo que sí se puede filmar es lo que rodea al campo de exterminio nazi, explorar los bordes. ${ }^{9}$ Para ello crea una ficción, una historia que aunque no sucedió nos 
revela distintos aspectos del hecho histórico traumático y ayudan a hacerlo comprensible. No hay imágenes de Auschwitz en Ave Fénix. Solo un breve flashback de Nelly Lenz con el traje a rayas en medio de fondo difuminado. No hay escenas de violencia, tampoco cae en la banalización. El realizador evita mostrar su rostro desfigurado, solo lo podemos intuir detrás de los vendajes. El universo de las cirugías estéticas reparadoras que podrían haber dado lugar al regodeo con lo monstruoso, sólo está denotado en las vitrinas del hospital pobladas de prótesis, aparatos, revistas científicas y elementos destinados a reparar en alguna medida los efectos de la destrucción. Sin golpes bajos nos enfrenta a las secuelas en los cuerpos provocadas por las guerras, los genocidios, las matanzas modernas.

Para Dominik LaCapra (2005, p. 208) la historiografía, la literatura, el arte y otras disciplinas tienen, cada una de ellas, maneras específicas de abordar la narración del trauma y "suscitan además preguntas provocadoras, tanto más apremiantes cuanto más tocan temas delicados, cargados de afectos y valores, como los que plantean los acontecimientos traumáticos límites". El mismo historiador, sugiere, que, pese a los riesgos que conlleva la imitación simbólica, es necesario no restringirse a los procedimientos estándar de la historiografía y explorar las distintas modalidades narrativas para exponer los sucesos traumáticos.

Si los pensadores citados se basaron en testimonios y documentos para acceder a la verdad de Auschwitz, el film de Petzold ilumina con imágenes y sonido esa parte de la realidad de la cual no hay registro. Ave Fenix, aunque no pertenezca al mundo histórico, nos conecta con la experiencia de los deportados, agregando nuevos significados sobre sus dificultades para dar sentido al sufrimiento padecido y para reconstruir su identidad, ante la indiferencia y la escasa disposición de los otros a escuchar su relato.

\section{Bibliografía}

Deleuze, G. (2005) La imagen movimiento Estudios sobre cine 1. Buenos Aires, Paidós.

Fulbrook, Mary (1995) Historia de Alemania, Cambridge, Cambridge University Press, Traducción española Beatriz García Ríos.

LaCapra, D (2005) Escribir la historia, escribir el trauma. Buenos Aires, Nueva Visión.

Loriga, S. (2018) Sobre el trauma histórico, Pasajes. Revista del pensamiento contemporáneo. Número 54 pp 92-110. En: https://www.academia.edu/38310490/T (Consultado 10 de enero de 2021)

Pollak, M (2006) Memoria, Silencio. Olvido. La producción social de identidades frente a situaciones límite. La Plata, Ediciones Al Margen.

Rees, L. (2005). Auschwitz Los nazis y la 'Solución final'. Barcelona. Crítica.

Romeyke,S.(2016) La justicia transicional en Alemania después de1945 y después de 1989, Academia Internacional de losPrincipiosde Núremberg. En: https://www.nurembergacademy.org/fileadmin/media/pdf/publications/Justicia_transicional_en_Alemania. pdf (Consultado el 10 de Diciembre de 2020) 
Stella, M (2018) "Holocausto, Memoria y justicia. Representaciones en el cine alemán de nuestros días" en Actas del VI Congreso Internacional de ASAECA. En: http://asaeca. org/wp-content/uploads/2017/11/Libro-de-actas-AsAECA-2018-2-1.pdf (consultado 12 de febrero de 2021).

Stella, M. (2019) "Holocausto y memoria en los tiempos de la globalización. Representaciones en el cine alemán" en Cine e Historia. Representaciones fílmica en un mundo globalizado. Centro de Estudios en Diseño y Comunicación. Universidad de Palermo, Cuaderno Número 77, Año 20.

Traverso, E. (2011), El pasado, instrucciones de uso, Buenos Aires, Prometeo.

\section{Ficha técnica}

Título original: Phoenix

Año: 2015

Duración: 98 min.

País: Alemania

Dirección: Christian Petzold

Guion: Christian Petzold, Harun Farocki. Novela: Hubert Monteilhet

Música: Stefan Will

Fotografía: Hans Fromm

Reparto: Nina Hoss, Ronald Zehrfeld, Uwe Preuss, Nina Kunzendorf, Michael Maertens, Uwe Preuss, Imogen Kogge, Eva Bay, Kirsten Block, Megan Gay, Valerie Koch.

Productora: Schramm Film Koerner \& Weber, Bayerischer Rundfunk (BR), Tempus, Arte, Westdeutscher Rundfunk (WDR)

Género: Drama

\section{Notas:}

1. La era Adenauer, 1949-1963, es la etapa que sigue a la creación de la República Federal Alemana, caracterizada por el fuerte impulso a la reconstrucción económica, con notables resultados, conocido como el "milagro alemán" y un decidido alineamiento con los Estados Unidos. En cuanto al pasado nazi se encaró una política de olvido y se frenaron los juicios penales.

2. Coherente con su idea de que la sociedad alemana debía enfrentar su responsabilidad, el Fiscal de Hesse impulsó por todos los medios que Eichmann fuera juzgado en Alemania, iniciativa que fue obstaculizada por los tres poderes del Estado.

3. https://lacinematecasevilla.wordpress.com/2012/01/31/la-escuela-de-berlin-el-jovencine-aleman-del-siglo-xxi/ 
4. Sobre todo, Petzold hacer referencia a Estados Unidos, cuyo cine produjo varias representaciones sobre el retorno de sus soldados luego la guerra, sobre todo de la guerra de Vietnam. Ver Entrevista al Director publicada en el diario Página 12 del 26 de marzo de 2015.

5. https://www.pagina12.com.ar/diario/suplementos/espectaculos/5-35072-2015-03-26. html (Consultado el 17 de enero de 2021)

6. Ídem anterior.

7. Pioneros en presentar las imágenes de los cuerpos de la guerra, fueron Ernst Jünger, en foto-libros de la Primera Guerra Mundial y Bertolt Brecht (2004), El ABC de la guerra, Madrid, Editorial Caracol.

8. Entre ellas, La máscara de fuego (Robert Florey, 1941); Los ojos sin rostro (Georges Franju, 1960); La piel que habito, (Pedro Almodóvar, 2011)

9. Uno de los filmes que aborda el tema es Wakolda, la película argentina de Lucía Puenzo (2013) basada en la novela homónima.

10. Ïdem Nota iv.

\begin{abstract}
The memory of the Shoah has followed a diachronic evolution of enormous magnitude. Indeed, from the misunderstanding and concealment of the event, in the immediate postwar period, it has become, in our days, the "civil religion of the West", according to Enzo Traverso (2011). This becoming is not disconnected from the new regime of historicity - the way a society relates to the temporal triad past, present and future - that affects politics and culture in the age of globalization.

For four decades, with the collapse of the idea of progress that Modernity sustained, the future lost its priority and guiding character and its place became occupied by the past, but not by a past from which it is possible to draw useful lessons. but rather a history full of genocides, wars, human rights violations, that is, a past that should be permanently remembered so that it does not repeat itself. A past, necessary, always present that prescribes the duty of memory.

The centrality of the violent past favored the incorporation of the category of trauma, which, imported from the field of psychoanalysis and the phenomena that influence the individual psyche, served to explain the acts of violence that affected large human groups. In this way, the traumatic event, the denial, the amnesia, the anamnesis and the return of the repressed were incorporated into the semantic field of the mass massacres of the 20th and 21st centuries, leaving said explanatory potential to history and social memory. (Rousso, 2015) he traumatic event -individual or collective- affects the construction of identity, exceeds the known frames of reference necessary for the narrative, breaks the causal chains with which people or groups elaborate the trauma.

The fall of the Berlin Wall, the following German reunification led to the process of elaboration of the violent past and the construction of a new pluralistic, democratic German identity, which takes over, judges and condemns the national socialist past.
\end{abstract}


The convergent processes, previously described, the different stages of the memory of the Shoah, the elaboration of the trauma and the construction of new group and individual identities are represented, among other audiovisual productions, but in a paradigmatic way in the film Ave Fenix, Directed by Christian Petzold, (2015), whose filmic analysis, images, discourses, its historical, social and cinematographic context will be dealt with in this article. Based on the novel by the French writer Hubert Monteilhet, Le retour des cendres, published in the early 1960s, Ave Fenix, is set in Germany in 1945 and narrates the return of a survivor from the Nazi concentration camps, a theme that According to the director, he had been eluded by German cinema and whose memory he deemed necessary to restore. The former prisoner returns from the horror, she not only with the trauma of the extreme experience lived, but with her face disfigured by a machine gun shot. The search for an elusive explanation, the difficulty of narrating what happened, the reconstruction of her identity and her face constitute the metaphor of collective trauma, the attempt to understand and elaborate the Holocaust.

Keywords: Holocaust - Survivors - Identity - Memory - Cinema.

Resumo: A memória da Shoah acompanhou uma evolução diacrônica de enorme magnitude. Com efeito, a partir da incompreensão e ocultação do acontecimento, no imediato pós-guerra, tornou-se, nos nossos dias, a "religião civil do Ocidente", segundo Enzo Traverso (2011). Esse devir não está desvinculado do novo regime de historicidade - a forma como uma sociedade se relaciona com a tríade temporal passado, presente e futuro - que afeta a política e a cultura na era da globalização.

Durante quatro décadas, com o colapso da ideia de progresso que sustentava a Modernidade, o futuro perdeu a sua prioridade e carácter norteador e o seu lugar passou a ser ocupado pelo passado, mas não por um passado de onde se possam tirar lições úteis. mas sim uma história cheia de genocídios, guerras, violações dos direitos humanos, ou seja, um passado que deve ser lembrado permanentemente para que não se repita. Um passado, necessário, sempre presente que prescreve o dever de memória.

A centralidade do passado violento favoreceu a incorporação da categoria do trauma, que, importada do campo da psicanálise e dos fenômenos que influenciam o psiquismo individual, serviu para explicar os atos de violência que atingiram grandes grupos humanos. Desse modo, o evento traumático, a negação, a amnésia, a anamnese e o retorno do reprimido foram incorporados ao campo semântico dos massacres em massa dos séculos XX e XXI, deixando esse potencial explicativo para a história e a memória social. (Rousso, 2015).

O evento traumático -individual ou coletivo- afeta a construção da identidade, ultrapassa os conhecidos referenciais necessários à narrativa, rompe as cadeias causais com as quais as pessoas ou grupos elaboram o trauma.

A queda do Muro de Berlim, a seguinte reunificação alemã conduziu ao processo de elaboração do passado violento e à construção de uma nova identidade alemã pluralista e democrática, que assume, julga e condena o passado nacional-socialista.

Os processos convergentes, anteriormente descritos, as diferentes etapas da memória da 
Shoah, a elaboração do trauma e a construção de novas identidades de grupo e individuais são representados, entre outras produções audiovisuais, mas de forma paradigmática no filme Ave Fénix, Dirigido por Christian Petzold, (2015), cuja análise fílmica, imagens, discursos, seu contexto histórico, social e cinematográfico serão tratados neste artigo.

Baseado no romance do escritor francês Hubert Monteilhet, Le retour des cendres, publicado no início dos anos 1960, Ave Fénix, se passa na Alemanha em 1945 e narra o retorno de um sobrevivente dos campos de concentração nazistas, tema que, segundo o diretor, fora iludido pelo cinema alemão e cuja memória julgou necessário restaurar. A exprisioneira volta do horror, não só com o trauma da experiência extrema que viveu, mas com o rosto desfigurado por um tiro de metralhadora. A busca de uma explicação elusiva, a dificuldade de narrar o acontecido, a reconstrução de sua identidade e de seu rosto constituem a metáfora do trauma coletivo, a tentativa de compreender e elaborar o Holocausto.

Palavras chave: Holocausto - Sobreviventes - Identidade - Memória - Cinema

[Las traducciones de los abstracts fueron supervisadas por el autor de cada artículo] 